\title{
Orthographic and Phonological Effects in the Picture-word Interference Paradigm: Evidence From a Logographic Language
}

\section{Citation}

$\mathrm{Bi}$, Yanchao, Yaoda Xu, and Alfonso Caramazza. 2009. Orthographic and phonological effects in the picture-word interference paradigm: Evidence from a logographic language. Applied Psycholinguistics 30(4): 637-658.

\section{Published Version}

doi:10.1017/S0142716409990051

\section{Permanent link}

http://nrs.harvard.edu/urn-3:HUL.InstRepos:5227811

\section{Terms of Use}

This article was downloaded from Harvard University's DASH repository, and is made available under the terms and conditions applicable to Other Posted Material, as set forth at http:// nrs.harvard.edu/urn-3:HUL.InstRepos:dash.current.terms-of-use\#LAA

\section{Share Your Story}

The Harvard community has made this article openly available.

Please share how this access benefits you. Submit a story.

\section{Accessibility}




\title{
Orthographic and phonological effects in the picture-word interference paradigm: Evidence from a logographic language
}

\author{
YANCHAO BI \\ Beijing Normal University \\ YAODA XU \\ Harvard University \\ ALFONSO CARAMAZZA \\ Harvard University and University of Trento
}

Received: May 22, 2008 Accepted for publication: March 6, 2009

\author{
ADDRESS FOR CORRESPONDENCE \\ Yanchao Bi, State Key Laboratory of Cognitive Neuroscience and Learning, Beijing Normal \\ University, Beijing 100875, People's Republic of China. E-mail: ybi@bnu.edu.cn
}

\begin{abstract}
One important finding with the picture-word interference paradigm is that picture-naming performance is facilitated by the presentation of a distractor (e.g., CAP) formally related to the picture name (e.g., "cat"). In two picture-naming experiments we investigated the nature of such form facilitation effect with Mandarin Chinese, separating the effects of phonology and orthography. Significant facilitation effects were observed both when distractors were only orthographically or only phonologically related to the targets. The orthographic effect was overall stronger than the phonological effect. These findings suggest that the classic form facilitation effect in picture-word interference is a mixed effect with multiple loci: it cannot be attributed merely to the nonlexical activation of the target phonological segments from the visual input of the distractor. It seems instead that orthographically only related distractors facilitate the lexical selection process of picture naming, and phonologically only related distractors facilitate the retrieval of target phonological segments.
\end{abstract}

The picture-word interference paradigm, a variant of the Stroop task (1935), has been widely used in psycholinguistic research, especially in the field of spoken word production (Glaser \& Dungelhoff, 1984; Glaser \& Glaser, 1989). In this paradigm, participants are required to name pictures that have distractor words superimposed upon them. Two kinds of picture-distractor relationships have been found to affect picture-naming performance. When the distractor word (e.g., DOG) belongs to the same semantic category as the picture (e.g., "cat"1), it takes longer

(C) 2009 Cambridge University Press 0142-7164/09 \$15.00 
to name the picture than when the distractor word is unrelated to the target (e.g., PEN). This has been called the semantic interference effect. When the distractor (CAP) is related to the picture name ("cat") by phonological properties, the picture is named more quickly than when it is accompanied by an unrelated distractor. This is commonly referred to as the phonological facilitation effect. The dominant interpretation of these two effects is that they reflect different processing levels of picture naming. The semantic interference effect is the result of competition at the lexical selection stage, and the phonological facilitation effect is because of the priming of the target phonological nodes by the distractor (e.g., Meyer \& Shriefers, 1991; Posnansky \& Rayner, 1978; Schriefers, Meyer, \& Levelt, 1990; Starreveld \& La Heij, 1995). Based on such assumptions, the paradigm has been used to develop various theories of lexical access, concerning both the organization and the dynamics of speech production.

However, the interpretations of both the semantic and the phonological effects are still controversial. For example, there is disagreement about the locus of the semantic interference effect: it has been argued that this effect does not reflect competition at the stage of lexical selection but interference at the stage of response selection (Costa, Mahon, Savova, \& Caramazza, 2003; Finkbeiner \& Caramazza, 2006; Janssen Schrim, Mahon, \& Caramazza, 2008; Mahon, Costa, Peterson, Vargas, \& Caramazza, 2007; Miozzo \& Caramazza, 2003). As for the phonological facilitation effect reported in the literature, it remains controversial whether this effect is the result of the priming of target phonological segments or the facilitation on earlier stages of target production (e.g., Damian \& Martin, 1999; Roelofs, Meyer, \& Levelt, 1996; Starreveld, 2000; Starreveld \& La Heij, 1995). However, there has always been a crucial confound in the study of the phonological effect in picture-word interference. Because almost all studies were conducted in alphabetic languages with medium to high grapheme-phoneme correspondence, the "phonological" distractor is also similar to the target word in visual form (consider CAP and "cat"), and therefore, it is unclear whether the facilitation effect produced by such distractors should be attributed to the phonological relatedness between target and distractor or the orthographic relatedness between target and distractor. Although Lupker (1982) conducted experiments to examine the contribution of orthographic versus phonological relatedness of the distractor to the target, his study has not received much attention, and the theoretical implications of the results have not been considered in depth (but see Roelofs et al., 1996). Instead, researchers have focused on the phonological aspect of the relationship and assumed that the facilitation is an output effect resulting from the priming of the target phonological nodes (e.g., Shriefers et al., 1990; Starreveld \& La Heij, 1995). ${ }^{2}$

Does the confounding of orthographic and phonological relatedness matter in the interpretation of the mechanism responsible for the observed facilitation effects? Detailed analyses of how an orthographically and/or phonologically related distractor may affect the target-naming process are presented below, using the example of the pairs "cat"/KEY and "cat"/CELL for phonological and orthographic relatedness, respectively.

Two kinds of processes need to be considered to determine how a distractor word may affect picture naming: the word perception process and the 
picture-naming process. It is widely accepted that the picture-naming process involves at least the following stages: concept activation, lexical selection, and phonological encoding. This generic model will be used as a guide in our current discussion. Although the received view of lexical access is that the lexical layer is further divided into a lemma layer, which specifies the syntactic properties of a word, and a lexeme layer, which specifies the syntactically determined morphemes (e.g., Bock \& Levelt, 1994; Dell, 1986; Garrett, 1980; Levelt, 1989; Roelofs, 1992, 1997) this view has been contested (Caramazza, 1997; Caramazza \& Miozzo, 1997; Caramazza, Costa, Miozzo, \& Bi, 2001). There is an unresolved controversy about the dynamics of the access process: whether activation flows between layers in a discrete (e.g., Levelt, Roelofs, \& Meyer, 1999), cascading (e.g., Caramazza, 1997), or interactive fashion (e.g., Dell, 1986). The consequences of adopting a distinction between a lemma and a lexeme level and of adopting feedback connections for the interpretation of the effects of distractors on picture naming will be discussed in the General Discussion.

On the word perception side, a written word is assumed to activate its orthographic, semantic, and phonological representations. The details of the activation flow among these representations have received much attention but remain controversial. Many models have been proposed, including logogen models (Morton, 1969), serial search, and verification models (Forster, 1976), interactive activation (McClelland \& Rumelhart, 1981), fuzzy logic models (Massaro \& Cohen, 1991), and so on. Here, the one assumption we are committed to is that of spreading activation. It is assumed that the lexical orthographic representation of the distractor word is always activated by the visual input. From the orthographic representation, the lexical phonological representation receives activation either through its semantic representation (e.g., Hillis \& Caramazza, 1995), or by direct lexical mapping between orthographic and phonological representations (e.g., Bub, Cancelliere, \& Kertesz, 1985). The semantic representation also receives activation, either directly from the lexical orthographic representation (e.g., Coltheart, 1978) or indirectly via phonology (e.g., Lukatela \& Turvey, 1994a, 1994b). The phonological segments that compose the word are activated both by the lexical phonological representation and through nonlexical graphemephoneme conversion (GPC) from the visual input. Although there is much debate in the literature on reading concerning the detailed timing and routes of activation among these representations, the central issue here is how the picture-naming process might be affected by a visual word input, namely, where and how the contact(s) between word- and picture-based processes occur.

Consider a distractor word that is phonologically, but not visually related to the target (KEY for "cat"). There are at least two ways in which the presentation of KEY may affect the naming of a picture of a "cat." One is that, upon seeing the word distractor, its lexical phonological representation /ki:/ is activated, either directly (Route P, Figure 1) or via its semantic representation. This lexical phonological representation, in turn, sends activation to its phonological segments $(/ \mathrm{k} /, / \mathrm{i}: /)$, parts of which (e.g., $/ \mathrm{k} /$ ) may be shared by the target. Also, the distractor can prime the target phonological segments through the GPC process. For instance, the grapheme " $k$ " in KEY activates the phoneme / $\mathrm{k} /$ through the GPC process, leading to the facilitation of phonological encoding of the target (Route G, Figure 1). 


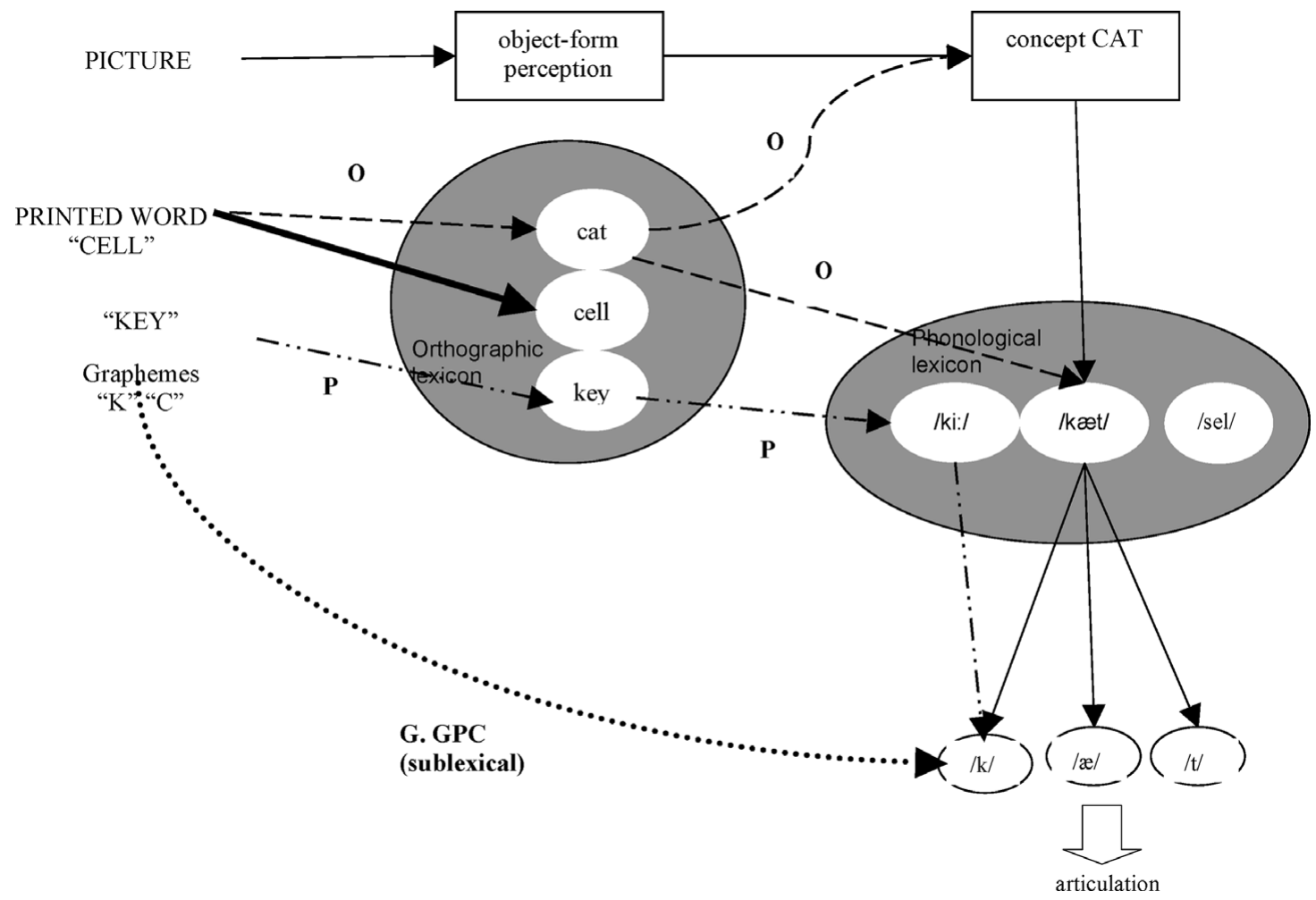

Figure 1. How a phonological distractor word (e.g., KEY) and an orthographic distractor (e.g., CELL) affects production ("cat"). Note: The connection between the corresponding items in the orthographic lexicon and the phonological lexicon could either be direct or via the conceptual system (see text). A direct line is drawn for the sake of simplicity. Orthographic lexical item CELL, once activated by the visual input, also activates its own semantic representation and phonological lexical representation. Only the activation that influences the target ("cat") is depicted. GPC, grapheme-phoneme conversion. 
Now consider an orthographically related word that does not share any phonology with the target, for example, the distractor CELL for the picture of "cat." Upon seeing the visual input CELL, the orthographic representations of all visual neighbors (CELL, CEILING, CALL, CAR, etc.) should be activated, including the target CAT (McClelland \& Rumelhart, 1981). The phonological lexical nodes of the activated orthographic representations are then activated either directly through orthographic to phonological lexical connections or through the semantic system (lexical orthographic to semantic to lexical phonological). Therefore, the target phonological lexical node "cat" is primed by the presentation of a visually similar distractor CELL (Route O, Figure 1). In some cases, the orthographic distractors can prime target phonological segments through the GPC process; in the present example, the grapheme "c" in CELL might activate the phoneme / $/ \mathrm{k}$, which is also part of the target's phonological content (Route G, Figure 1).

The point of this analysis is that there are multiple potential routes that are responsible for the facilitation effect observed with phonologically and orthographically related distractors (e.g., CAP for "cat"). An important study that shed light on the contributions of these possible routes was conducted by Lupker (1982). In two picture-word experiments conducted in English, Lupker tried to distinguish the contribution of the orthographic and phonological relatedness of the distractor on the processing of the target. He found that both phonologically (but not orthographically) related distractors and orthographically (but not phonologically) related distractors facilitated picture naming. In Experiment 1, each picture (e.g., "bear") was paired with a distractor with similar orthography and different phonology (e.g., YEAR), or an unrelated distractor (e.g., WORK), or nonwords with different degrees of orthographic similarity (e.g., XXXT, XXR, or DFRP). In Experiment 2, the picture targets (e.g., "plane") were paired with distractors of similar phonology and different spelling (e.g., BRAIN), distractors sharing both sound and spelling (e.g., CANE), unrelated words, and nonwords with orthographic and phonological properties parallel to the word conditions. Lupker's (1982) major findings were the following: (a) phonological distractors facilitated picture naming (by $23 \mathrm{~ms}$ in Experiment 2); (b) orthographically similar distractors facilitated picture naming (by $56 \mathrm{~ms}$ in Experiment 1); and (c) when both orthography and phonology were shared between distractor and picture name, the magnitude of the facilitation effect (55 $\mathrm{ms}$ in Experiment 2) was similar to that found when only orthography was shared (56 ms in Experiment 1). As discussed above, an orthographic distractor ("bear"-YEAR) may affect either the target lexical node or its phonological segments through GPC processes. The fact that facilitation from these kinds of distractors was indeed observed suggests that either or both of these processing layers are affected in the picture-word naming task. Similarly, the observed facilitation effect from phonologically related distractors ("plane"-BRAIN) suggests that the phonological content of the target is primed.

However, we need to view these results with caution. Because it is difficult to disentangle orthography and phonology in English, the orthographically related pairs sometimes also share phonological properties and the phonologically related pairs sometimes share orthographic properties. In addition, the item sets in the experiments were rather small-12 pictures in Experiment 1 and 9 pictures in Experiment 2. Because item analyses were not performed in the study, it is not 
clear how reliable the results are over different items. Furthermore, the observation that the magnitude of the orthographic facilitation effect is similar to that of the orthographic plus phonological effect, and is larger than that of the phonological facilitation effect, is based on "eyeball" comparisons across two experiments with different stimuli and participants. Thus, it is not obvious that these differences in the magnitude of effects are interpretable.

Two studies (Weekes, Davies, \& Chen 2002; Zhou, Zhuang, Wu, \& Yang, 2003) have attempted to more clearly separate the effects of orthographic and phonological relatedness by using Chinese. The basic writing units of Chinese are characters, which are logographic in nature with highly arbitrary symbol-sound correspondence (e.g., DeFrancis, 1989; Li, 1993; Wang, 1973; Yin \& Rohsenow, 1994; Zhou, Shu, Bi, \& Shi, 1999). Two related characteristics of the language make it ideal for the study of phonological and orthographic effects in picture naming. Because symbol-sound correspondence is highly opaque in general, and is completely arbitrary for many characters, one can test whether the orthographic and phonological facilitation effects still exist when target phonology cannot be primed through a GPC route. Furthermore, it is common to find homophones with distinct visual forms (e.g., the first character of the word 狐狸 $<$ fox $>$ and 壸 $<$ kettle $>$, both pronounced as $/ \mathrm{hu} 2 /^{3}$ ), or two orthographically similar characters with different pronunciations (e.g., 狐 $<$ fox $>$, /hu2/ vs. 呱 $<$ quack $>$, /gua $1 /$ ). Therefore, Chinese offers the opportunity to manipulate phonological and orthographic relatedness in a factorial design, thereby allowing us to identify the locus or loci of the putative phonological facilitation effect (e.g., Chen, Cheung, \& Flores d'Arcais, 1995; Cheng \& Shih, 1998; Feng, Miller, Shu, \& Zhang, 2001; Hue, 1992; Perfetti \& Tan 1998; Shen \& Forster, 1999; Wong \& Chen, 1999; Zhou \& Marslen-Wilson, 1999a; Zhou, Marslen-Wilson, Taft, \& Shu, 1999).

The primary goal of Weekes et al.'s (2002) study was to investigate the locus of the semantic interference effect by comparing it with the orthographic/phonological effects. Similarly to Lupker (1982), they found that both orthographically only and phonologically only related distractors produced significant effects. However, contrary to Lupker's study, the magnitudes of the two effects were comparable and the phonological and the orthographic effects were additive. In Zhou et al.'s (2003) study, they reported that the phonological effect was larger than the orthographic effect, although no direct statistical comparison was carried out between these two conditions. The interaction between these two types of effects was not assessed. There are certain methodological limitations in these studies, however. Weekes et al. (2002) did not control the visual complexity of distractors in different conditions nor the degree of orthographic/phonological similarity across conditions (B. S. Weekes, personal communication, 2008). Zhou et al. (2003) constructed the unrelated condition by pairing the orthographic distractors with targets. Hence, the three types of distractors (phonologically, orthographically, and semantically related distractors) were presented in the experiment an unequal number of times: orthographically related distractrors were presented twice as often as the other distractors. This makes a direct comparison of the phonological and orthographic distractors problematic because the fact that orthographic distractors led to less interference than phonological distractors in picture naming may be an effect of distractor repetition and not a difference 
between phonology and orthography. This difference in distractor repetition might temporarily change the activation level of distractor words. In addition, given that lexical activation levels modulate the word interference effect in the word-picturenaming paradigm (see the distractor word frequency effect; Miozzo \& Caramazza, 2003), the orthographic and the phonological effects might be contaminated by a possible distractor word repetition effect.

More critically for the theoretical interpretations of the orthographic/ phonological effects, in these two studies the authors did not explicitly manipulate or control for the potential GPC factor. Although Chinese has highly opaque symbol-sound correspondences, it has been proposed that GPC or a GPC-like mechanism is not completely absent in Chinese. Over $80 \%$ of modern Chinese characters are so-called "compound characters" composed of a "semantic radical" and a "phonetic radical" (Perfetti \& Tan, 1998; Zhu, 1988). The semantic radical relates to the meaning, typically the semantic category of the character. The phonetic radical, which is usually also a Chinese character by itself, provides cues to the pronunciation of the whole character, although these cues are often unreliable. The position of the phonetic radical is not fixed either. Studies have shown that in reading such compound characters, the phonological properties of the phonetic radicals are automatically activated and influence reading performance (e.g., Bi, Han, Shu, \& Weekes, 2007; Hue, 1992; Law \& Wang, 2005; Lee et al., 2004; Lee, Tsai, Su, Tzeng, \& Huang, 2005; Peng, Yang, \& Chen, 1994; Seidenberg, 1985; Shu \& Zhang, 1987; Weekes \& Chen, 1999; Yin \& Butterworth, 1992; Zhou \& Marslen-Wilson, 1999b; but see Coltheart, Rastle, Perry, Langdon, \& Ziegler, 2001). It remains controversial whether such a GPC-like procedure, which is often referred to as a "sublexical" mechanism, is nonlexical or lexical in nature (see Zhou \& Marslen-Wilson, 1999b). For our current purposes what is relevant is whether orthographic and/or phonological distractors might affect target production without going through their corresponding lexical representations. In other words, the point is whether procedures similar to Route $\mathrm{G}$ in Figure 1 can be applied in the Chinese experiments. If yes, it would influence the interpretation of the effects in the following ways. If the orthographic distractors are compound characters and the phonetic radical is phonologically similar to the target name, the orthographic effect could have resulted from sublexical processes (Route G, Figure 1) alone, or the combination of the sublexical and the "lexical" routes (Route $\mathrm{O}$ ). Similarly, If phonological distractors are compound characters and the phonetic radicals in these characters were phonologically similar to the target name, then the phonological effect could have resulted from sublexical (Route G, Figure 1) alone or the combination of sublexical $(\mathrm{G})$ and the "lexical phonology" routes (Route P). In light of these considerations, it is important to control for such potential GPC-like sublexical origins for the phonological/orthographic effects even in experiments using Chinese, and this is what we did here.

In this article, we report two experiments using Mandarin Chinese to further investigate the mechanisms responsible for the putative phonological/orthographic facilitation effect. We paired each target picture with an unrelated distractor or a distractor that is related to the picture's name only orthographically, only phonologically, or both orthographically and phonologically. Critically, the distractors were constructed in a way to maximally reduce the application of GPC-like 
mechanisms. The rationale is as follows: if the phonological facilitation effect is merely because of the activation of the phonological segments through GPC processes (Route G, Figure 1), we should not find facilitation effects in any of the related conditions because the nonlexical symbol-sound correspondence is not applicable for our Chinese stimuli; the target phonemic segments do not receive direct activation via GPC from the visual input of the written distractor. If we do observe a facilitation effect from the phonologically only related distractors, it could only arise through the "lexical phonology route" (Route P). This is because the phonologically only related distractors (e.g., 壸 $<$ kettle $>/$ hu2/) share with the target items (“狐㹤” $<$ fox $>$, /hu2-li0/) nothing but phonological properties. Furthermore, there is no visual information of these distractors (声, $<$ kettle $>$ ) that could provide cues for the target sound (/hu2/) through any nonlexical GPC process. A possible explanation for such an outcome is that the visual form activates the lexical phonological representation (壸, $<$ kettle $>$, /hu2/), which in turn, activates the phonetic segments shared with the target ("狐猖," $<$ fox $>/$ hu2-li0/). If we observe a facilitation effect from a distractor that is related to the target only orthographically (e.g., 呱 <quack>, /gua1/) and if the contribution of GPC process is ruled out, we would have to attribute the cause of such an effect to processes internal to the "lexical route" (Route $\mathrm{O}$ ).

\section{EXPERIMENT 1}

\section{Method}

Participants. Twenty-five native speakers of Mandarin Chinese at Beijing Normal University served as paid participants.

Materials. The experiment included 19 pictures (line drawings) of common objects from the Snodgrass and Vanderwart (1980) picture set and Cognitive Neuropsychology Laboratory collections. The names for 4 of the pictures were monosyllabic words, 14 were bisyllabic words, and 1 had three syllables. Each picture was paired with four types of distractor words, all of which were monosyllabic: (a) $O+P+$, a word that was both orthographically and phonologically related to the picture name; (b) $O-P+$, a word that was phonologically related but orthographically dissimilar to the picture name; (c) $O+P-$, a word that was orthographically related but phonologically dissimilar to the picture name; and (d) $\mathrm{O}-\mathrm{P}-$, a word that was neither orthographically or phonologically related to the picture name. The characters in the four distractor conditions were matched on word frequency (Institute of Language Teaching and Research, 1986) and visual complexity (number of strokes), as shown in Table 1.

In the orthographically related conditions $(\mathrm{O}+\mathrm{P}+$ and $\mathrm{O}+\mathrm{P}-)$, each distractor word and the first syllable of its corresponding target picture name shared at least half the visual components (or radicals). For instance, according to "Hanzi Xinxi Zidian" (Chinese Characters Information Dictionary; Li \& Liu, 1988), character 绵 ( $<$ soft $>$ ) is composed of visual components “价 on the left, “白” on the top right, and “巾” on the bottom right. Character 棉 $(<$ cotton $>)$ ) shares the two components on the right “白” and “中” with 绵 $(<$ soft $>)$. In the phonologically related conditions 
Table 1. Sample stimuli and mean values of frequency and visual complexity in Experiments 1 and 2

\begin{tabular}{llccccc}
\hline \hline & & \multicolumn{4}{c}{ Type of Distractors } \\
\cline { 3 - 6 } & & Picture Name & $\mathrm{O}+\mathrm{P}+$ & $\mathrm{O}+\mathrm{P}-$ & $\mathrm{O}-\mathrm{P}+$ & $\mathrm{O}-\mathrm{P}-$ \\
\hline & Meaning & Sheep & Cotton & Brocade & Sleep & Continue \\
& Pronunciation & /mian2 yang2/ & $/$ mian2/ & /jin3/ & $/$ mian2/ & $/$ xu4/ \\
Exp. 1 & Frequency & & 127 & 355 & 246 & 190 \\
& No. of strokes & & 9.4 & 10 & 9.3 & 9.8 \\
Exp. 2 & Frequency & & 80 & 962 & 398 & 145 \\
& No. of strokes & 10 & 10 & 10 & 10 \\
\hline \hline
\end{tabular}

Note: $\mathrm{O}+\mathrm{P}+$, a word that was both orthographically and phonologically related to the picture name; $\mathrm{O}-\mathrm{P}+$, a word that was phonologically related but orthographically dissimilar to the picture name; $\mathrm{O}+\mathrm{P}-$, a word that was orthographically related but phonologically dissimilar to the picture name; and $\mathrm{O}-\mathrm{P}-$, a word that was neither orthographically or phonologically related to the picture name.

$(\mathrm{O}+\mathrm{P}+$ and $\mathrm{O}-\mathrm{P}+)$, each distractor word and the first syllable of its corresponding target picture name had the same vowel and consonant. For most cases the pair also had the same tones. None of the distractors was semantically related to the target picture. Care was taken to ensure that the distractor words in the three related conditions $(\mathrm{O}+\mathrm{P}+, \mathrm{O}+\mathrm{P}-, \mathrm{O}-\mathrm{P}+)$ did not contain phonetic radicals that were homophonic to the name of the target picture. For example, for the picture of a pond, whose name is “池塘”, the first syllable of the picture name is “池”/chi2/, and the phonetic radical "也”" in the $\mathrm{O}+\mathrm{P}+$ and $\mathrm{O}+\mathrm{P}-$ conditions is pronounced /ye3/, whereas the phonetic radical “寺” in the $\mathrm{O}-\mathrm{P}+$ condition is pronounced $/ \mathrm{si} 4 /$.

Thirty pictures from the same picture corpus were selected as fillers and warmup items. About one-third had one-syllable names and the rest had bisyllabic names. Each of the pictures was paired with four unrelated distractors. All the distractors were monosyllabic.

The four types of word distractors for all of the 49 pictures were assigned into four blocks according to the Latin-square method so that each picture appeared in each block once, and there were about an equal number of picture-distractor pairs from each condition in each block. Different pseudorandom orders were generated for each block such that no more than two successive trials were of the same experimental condition and that successive pictures were not semantically or phonologically related. For half of the participants, the order of trials in each block was reversed. Each participant saw all four blocks. The presentation order of the four blocks to the participants was assigned according to the Latin-square method.

All of the pictures were about $8 \times 8 \mathrm{~cm}$ black line drawings on a white background. The distractors were randomly presented at nine locations around the center of the picture, in 24-point Song Black font. 
Procedure and apparatus. Stimulus presentation and reaction time (RT) recording were controlled by the dual screen version of DMDX (Forster \& Forster, 2003). There was a familiarization session, a practice session, and the experiment proper. In the familiarization session the pictures were presented one by one for $700 \mathrm{~ms}$ followed by the name printed in the center of the screen. The participants were instructed to use the given name to name the pictures in the experiment. In the practice session, a picture was paired with an unrelated character that was not shown in any of the experimental conditions. On each trial of the experimental and practice sessions the following events occurred: a fixation point "+" appeared in the center of the screen for $700 \mathrm{~ms}$, and then was replaced by the picture with distractors superimposed, which was presented for $700 \mathrm{~ms} ; 2 \mathrm{~s}$ after the oral response, or $4 \mathrm{~s}$ in case of no response, the next trial started with the fixation point. Errors were recorded manually by the experimenter. The entire experiment lasted about $40 \mathrm{~min}$.

\section{Results and discussion}

The data of one participant were discarded because of too many voice-key failures (over 50\%). Naming latencies were discarded from the analyses whenever any of the following occurred: (a) a picture was named incorrectly, (b) a dysfluency occurred or an utterance was repaired, (c) RTs deviated from a participant's mean by more than $3 S D$, and (d) voice-key failed to trigger. In total $5.3 \%$ of the trials (3.0\% errors, $1.3 \%$ outliers, and $0.9 \%$ voice-key failures) were excluded from the analysis. Mean RTs, standard deviations, and error rates of the four conditions are listed in Table 2. The overall error rates were considered to be too low to be statistically analyzed.

A $2(\mathrm{O}+$ vs. $\mathrm{O}-) \times 2(\mathrm{P}+$ vs. $\mathrm{P}-)$ analysis of variance was carried out. Subjects and items were treated as random variables to generate $F 1$ and $F 2$ analyses, respectively. The main effect of phonological similarity was significant: $F 1(1,23)=$ 6.7 , mean square error $(M S E)=452, p<.05 ; F 2(1,18)=5.8, M S E=560, p<$ .05 ; the main effect of orthographic similarity was significant: $F 1(1,23)=42.9$, $M S E=1056, p<.0001 ; F 2(1,18)=57.9, M S E=714, p<.0001$; and there was also a significant interaction effect between these two factors: $F 1(1,23)=$ 7.6, $M S E=713, p<.05 ; F 2(1,18)=5.3, M S E=883, p<.05$.

Pairwise comparisons showed that the orthographic-only related distractors produced a significant facilitation effect $(\mathrm{O}+\mathrm{P}-$ vs. $\mathrm{O}-\mathrm{P}-): F 1(1,23)=53.3$, $M S E=770, p<.001 ; F 2(1,18)=29.4, M S E=1254, p<.001$, and so did the phonologically only related distractors $(\mathrm{O}-\mathrm{P}+$ vs. $\mathrm{O}-\mathrm{P}-): F 1(1,23)=$ $11.4, M S E=725, p<.01 ; F 2(1,18)=8.0, M S E=976, p<.05$. The effect produced by the orthographic-only distractors was larger than that produced by the phonological-only distractors $(\mathrm{O}+\mathrm{P}-$ vs. $\mathrm{O}-\mathrm{P}+): F 1(1,23)=16.3, M S E=$ $764, p<.001 ; F 2(1,18)=24.0, M S E=447, p<.001$. When the distractors were orthographically and phonologically related to the target, there was no additional benefit for the presence of both forms of similarity $(\mathrm{O}+\mathrm{P}+$ vs. $\mathrm{O}+\mathrm{P}-): F \mathrm{~s}<1$.

The results fully replicated those of Lupker (1982), showing that orthographic relatedness and the phonological relatedness affect picture naming even when the nonlexical GPC processes are ruled out. However, there seems to be one puzzling 
Table 2. Mean reaction time ( $R T)$, standard deviation $(S D)$, and error rates $(E R R)$ in Experiments 1 and 2

\begin{tabular}{llcccc}
\hline \hline & & \multicolumn{4}{c}{ Type of Distractors } \\
\cline { 3 - 6 } Picture Name & & $\mathrm{O}+\mathrm{P}+$ & $\mathrm{O}+\mathrm{P}-$ & $\mathrm{O}-\mathrm{P}+$ & $\mathrm{O}-\mathrm{P}-$ \\
\hline 绵羊 & & 棉 & 锦 & 眠 & 续 \\
/mian2 yang2/ & Pronunciation & $/ \operatorname{mian} 2 /$ & $/ \mathrm{jin} 3 /$ & $/ \mathrm{mian} 2 /$ & $/ \mathrm{xu} 4 /$ \\
Exp. 1 & Mean RT (ms) & 755 & 752 & 785 & 812 \\
& SD & 53 & 62 & 63 & 63 \\
& Effect (ms) & $57 * *$ & $60 * *$ & $27 *$ & \\
Exp. 2 & ERR (\%) & 2.0 & 2.2 & 3.3 & 3.5 \\
& Mean RT (ms) & 647 & 665 & 686 & 719 \\
& SD & 14 & 16 & 14 & 15 \\
& Effect (ms) & $72 * *$ & $54 * *$ & $23 *$ & \\
& ERR (\%) & 2.4 & 2.1 & 1.8 & 1.8 \\
\hline \hline
\end{tabular}

Note: $\mathrm{O}+\mathrm{P}+$, a word that was both orthographically and phonologically related to the picture name; $\mathrm{O}-\mathrm{P}+$, a word that was phonologically related but orthographically dissimilar to the picture name; $\mathrm{O}+\mathrm{P}-$, a word that was orthographically related but phonologically dissimilar to the picture name; and $\mathrm{O}-\mathrm{P}-$, a word that was neither orthographically or phonologically related to the picture name.

$* p<.05 . * * p<.01$.

result in both our experiment and in Lupker's (1982) English experiments: the magnitude of the facilitation effect produced by a distractor that was both orthographically and phonologically related to the target $(\mathrm{O}+\mathrm{P}+)$ was similar to that of the effect produced by an orthographic-only related distractor $(\mathrm{O}+\mathrm{P}-)$. No additional effect of phonological relatedness was observed when orthography was shared between the distractor and the target. Although the interpretation we offered in the introductory section predicts that the two effects could interact to some degree because they share at least one component (priming at the level of phonological segments), the models presented in Figure 1 cannot provide a straightforward explanation of why there is no additional priming of the phonological segments on top of the orthographic effect. We speculated that the absence of such additional phonological effect might be because of a floor effect. There is limited room for speeding up the target naming process, and the facilitation effect produced by orthographic relatedness is so large that any other effect would be less visible. Experiment 2 was then conducted to replicate the results in Experiment 1 with a new set of stimuli, especially to examine whether the absence of difference between the $\mathrm{O}+\mathrm{P}+\mathrm{vs}$. $\mathrm{O}+\mathrm{P}-$ conditions was reliable.

\section{EXPERIMENT 2}

\section{Method}

Participants. Twenty native speakers of Mandarin Chinese at Beijing Normal University served as paid participants. 
Materials. Ten pictures from Experiment 1 and 9 new pictures were selected as targets. Each were paired with distractors that were not used in Experiment 1 (see Table 1). Twenty-five new fillers pictures were also included each paired with four unrelated distractors. The aspects of stimuli construction are identical to those of Experiment 1.

Procedure and apparatus. These were identical to those of Experiment 1.

\section{Results and discussion}

Following the criteria used in Experiment $1,3.6 \%$ of the trials $(2.0 \%$ erroneous responses, $1.5 \%$ outliers) were excluded from the analysis. Mean RTs and error rates of the four conditions are listed in Table 2. Because the error rates in this experiment is very low only RT analyses were carried out.

The main effect of phonological similarity was significant: $F 1(1,19)=35.04$, $M S E=371, p<.001 ; F 2(1,18)=15.69, M S E=741, p<.001$; the main effect of orthographic similarity was significant: $F 1(1,19)=102.72, M S E=442, p<$ $.001 ; F 2(1,18)=20.19, M S E=2109, p<.001$; The interaction between did not reach significance level: $F 1(1,19)=2.19, M S E=476, p=.155 ; F 2(1,18)=$ $1.33, M S E=824, p=.264$.

Pairwise comparisons showed that the orthographic-only related distractors produced a significant facilitation effect $(\mathrm{O}+\mathrm{P}-$ vs. $\mathrm{O}-\mathrm{P}-): F 1(1,19)=47.36$, $M S E=611, p<.001 ; F 2(1,18)=15.86, M S E=1807, p<.001$, and so did the phonologically only related distractors $(\mathrm{O}-\mathrm{P}+\mathrm{vs}$. $\mathrm{O}-\mathrm{P}-)$ : $F 1(1,19)=19.10$, $M S E=560, p<.001 ; F 2(1,18)=8.95, M S E=1109, p=.08$. The effect produced by the orthographic-only distractors was larger than that produced by the phonological-only distractors $(\mathrm{O}+\mathrm{P}-$ vs. $\mathrm{O}-\mathrm{P}+): F 1(1,19)=13.6, M S E=$ $326, p<.01 ; F 2(1,18)=2.85, M S E=1702, p=.10$. When the distractors were orthographically and phonologically related to the target, an additional benefit for the presence of both forms of similarity was observed $(\mathrm{O}+\mathrm{P}+$ vs. $\mathrm{O}+\mathrm{P}-)$ : $F 1(1$, $19)=11.63, M S E=287, p<.003 ; F 2(1,18)=6.14, M S E=456, p<.05$.

The results of Experiment 2 further replicated the major findings in Experiment 1 such that both orthographic and phonological distractors facilitated picture naming when the contribution of GPC processes is ruled out. Furthermore, a small, but significant difference between the response latencies of the $\mathrm{O}+\mathrm{P}+$ and the $\mathrm{O}+\mathrm{P}-$ conditions was observed, whereas there was no difference in terms of error rates. In other words, the lack of difference between these two conditions in Experiment 1 was not replicated. However, the overall RTs in this experiment were shorter than those in Experiment 1, making a simple "floor effect" argument not too feasible. Rather, it could be that this difference $(\mathrm{O}+\mathrm{P}+$ and $\mathrm{O}+\mathrm{P}-)$ is too weak to be obtained reliably. We acknowledge that we do not have a specific explanation, and whether it can be observed might depend on certain characteristics of particular item sets or subject groups.

\section{GENERAL DISCUSSION}

In two picture-word interference experiments we investigated the nature of the classic phonological facilitation effect, separating the effects of phonology and 
orthography by taking advantage of the logographic nature of Mandarin Chinese. It was critical that any potential contribution from the GPC procedure was ruled out. We repetitively observed that phonological-only related distractors significantly facilitated target picture naming. Orthographic-only related distractors produced an even larger facilitation effect on target naming. The additional phonological effect on top of an orthographic effect was observed in Experiment 2 but not in Experiment 1, suggesting that such additional phonological effect is small and unreliable. Below we will focus on the first two reliable results. We will first compare these results with other relevant studies in the literature, then we will analyze the possible mechanisms of the orthographic and the phonological effects within different speech production frameworks, and finally, we will address the theoretical implications of the results in the broader context of speech production research.

The major findings in our results replicated the findings in Lupker (1982) and Zhou et al. (2003) while avoiding their methodological limitations. Weekes et al. (2002) also found that both orthographic-only and phonological-only distractors produced significant facilitation effects on picture naming but in their study the magnitudes of these two effects were comparable. It is possible that the orthographic distractors in Weekes et al.'s study did not have as high degree of visual similarity to the targets as ours (and Zhou et al.'s, 2003). If this were the case, then although in all these studies, the degree of similarity was higher for the phonological manipulation (near 100\%) than the orthographic manipulation, the difference was even stronger in Weekes et al., making the direct comparison of the magnitudes of the two effects in their study less meaningful. Unfortunately, the original stimuli used in Weekes et al. (2002) are not available for further analyses.

One important contribution of our experiments beyond these previous studies (Lupker, 1982; Weekes et al., 2002; Zhou et al., 2003) is that only in our study was the contribution of GPC processes clearly ruled out. In our experiments the facilitation effects were robust even when the contribution from the nonlexical GPC or sublexical processes was ruled out. We can conclude more confidently from these results that the orthographic/phonological facilitation effects obtained in the literature cannot be attributed merely to the activation of target phonetic segments by a written distractor via GPC processes (Route G, Figure 1). For the orthographic-only related distractors, the facilitation effect can only result from the "lexical route" (Route $\mathrm{O}$ ). This conclusion is based on the assumption that the written distractors cannot activate the target phonetic segments via the nonlexical GPC route (Route G) or directly from the distractors' lexical phonological representation (Route P) because they are not phonologically related to the targets. The written form of the distractor (e.g., 呱, <quack>, /gua1/) activates the orthographic representation of 呱, and also other visually similar orthographic representations, including that of the picture target 狐狸. The activation would spread to the semantic, lexical phonology, and phonetic segments of the target, resulting in faster selection/retrieval of the target item in these stages. Note that this "phonological" lexical node in the generic model roughly corresponds to the lexical node in the Independent Network model (Caramazza, 1997) and the wordform layer in the model proposed by Starreveld and colleagues (e.g., Starreveld, 2000; Starreveld \& La Heij, 1995, 1996). 
In the above discussion we have discussed the mechanisms of the form facilitation effects in the generic framework of word production. We mentioned in the introductory section that there are ongoing debates both regarding the overall architecture of the lexical system and the dynamics of lexical access. The two most important notions that differ from our generic model are the following: (a) the lexical layer is further divided into a lemma level and a lexeme level, and (b) there are feedback connections in the system. The consequences of these two assumptions will be discussed in turn.

We utilize WEAVER ++ proposed by Levelt and colleagues (1999) as an example of models of two lexical layers. In WEAVER++, after a lexical concept node is selected, it sends activation to the corresponding lemma and the lemmas of related concepts, which specify the syntactic properties of words. Upon the selection of the most active lemma, the activation flows to its corresponding lexeme. This is followed by the encoding of the phonological segments associated with a particular lexeme. Activation travels across different layers in a discrete manner. There are two possible routes in WEAVER ++ for a phonological-only distractor to affect target naming. First, the phonological lexeme of the distractor is activated by the visual input. If the distractor is a homophone of the target, this lexeme is also the target lexeme. When the target and distractor are not homophonous (e.g., “狐” (/hu2/, fox)" and 魂 (/hun2/, spirit)), it is not obvious whether the lexeme of “/hu2/" could be activated by 魂 (/hun2/) aside from the shared phonological segments (e.g., /h/). Second, target phonological segments can also be primed by the distractor through GPC processes when applicable. For an orthographic-only related distractor, Roelofs et al. (1996) argue that at the very least it primes the target lemma. Upon seeing the visual input, the orthographic representations (orthographic lexeme) of all visual neighbors should be activated, including the target. Once the target orthographic lexeme is activated, the activation will spread to the target lemma, which is shared by the perception and speech production networks. Because of the assumption of WEAVER ++ that "the distractor word affects the corresponding morpheme (lexeme) node in the production network," the target orthographic lexeme, activated by an orthographic distractor will also prime the target phonological lexeme directly. In other words, the target lemma and phonological lexeme are both primed by the presentation of an orthographic distractor. Furthermore, in some cases, nonlexical GPC may also lead to the priming of target phonological segments by orthographic distractors (e.g., consider the distractor PLANE for the target "brain"). In summary, in WEAVER++, the orthographic effect could be attributed to the priming of target lemma and lexeme, and also priming of the phonological segments via GPC processes; the phonological effect could be attributed to the priming of target lexeme and target phonological segments.

Another important consideration about the nature of the lexical access process concerns assumptions about mechanism of activation flow: some theories assume bidirectional connections between processing levels (e.g., Dell, 1986; Rapp \& Goldrick, 2000). These theories assume that a later processing 
level of representation can affect an earlier level through feedback connections between layers. Within such a framework, it is hard to attribute the phonological and the orthographic effects to a specific locus (or loci). For instance, even if a phonological distractor starts to affect target naming at the phonological segments level, there is nothing in the model to prevent the spreading of activation back to the lexical layer and affect lexical node selection. At best, once all parameters of a model are specified, such as the strength of the feedback connection, it might be possible to deduce through computational simulations what percentage of the observed effect are the result of facilitation on a given stage.

Starreveld (2000) has produced an especially useful summary of the various accounts that have been offered in the literature for the orthographic/phonological effect in picture-word interference, including the phonological-segment view (Meyer \& Shriefers, 1991), the "lemma-activation" view (Roelofs et al., 1996), and the "word-form" view (Starreveld, 2000; Starreveld \& La Heij, 1995). Starreveld and La Heij (1996; Starreveld, 2000) have shown that the orthographic/phonological effect is obtained over a wide range of stimulus onset asynchronies and that it interacts with the semantic effect (Starreveld \& La Heij, 1995; also see Damian \& Martin, 1999). They have gone on to propose that the orthographic/phonological effect should be localized at the word-form layer. However, by showing a "pure" phonological effect (Route P, Figure 1) and a "pure" orthographic effect (Route $\mathrm{O}$ ), we have direct empirical evidence that the classical orthographic/phonological effect reported in the literature is a mixture of effects arising at multiple stages, including the lexical layer(s) (both lemma and lexeme) and the phonological segments.

Before we discuss the broader theoretical implications of these findings, we have to analyze whether and how much of the results and conclusions about picture-word interference based on the Mandarin Chinese experiments can be generalized to alphabetic languages. There is neither empirical evidence nor theoretical grounds for holding that the speech production (picture naming) process in Mandarin is different from that of alphabetic languages (e.g., English). It might be more reasonable to ask if the word perception process of the distractors might differ in these two kinds of language systems, resulting in possible differences in the mechanism of picture-word interference. There is a substantial literature investigating how Mandarin words are recognized and whether this process differs from alphabetic languages (mostly English). Just as in English, there are debates on the detailed timing and routes of activation between the orthographic, the phonological, and the semantic representation, such as whether phonology mediates semantic access in visual word recognition (e.g., Perfetti \& Tan, 1998; Perfetti \& Zhang, 1995; Tan, Hoosain, \& Peng, 1995; Zhou \& Marslen-Wilson, 1999a). There is much evidence that phonological information is obligatorily activated in reading Chinese (Mandarin) (e.g., Perfetti \& Tan, 1998; Zhou \& Marslen-Wilson, 1999a; Zhou et al., 1999), and that the semantic activation is driven by both orthographic and phonological information. To be conservative on the universality notion of language processing, it could be 
argued that in English, phonology seems to play a primary role in semantic access, whereas in Chinese, orthographic information might be more important (Zhou \& Marslen-Wilson, 1999a). If such were the case, we would expect that the orthographic effect in picture-word naming would be stronger in Chinese and the phonological effect would be stronger in English. Similarly, one could also imagine that the effect through GPC is more dominant in alphabetic languages than in Chinese. However, these possibilities are not encouraged by the results of Lupker (1982), and they should not affect the ways such effects occur either.

Another difference between English and Mandarin word recognition is the nature of sublexical phonological activation (GPC). It has been found that in Chinese, in the process of perceiving a character, both the semantic and the phonological properties of the phonetic radical are activated (e.g., Zhou \& MarslenWilson, 1999b), whereas in English, only the phonology but not the semantic content of the sublexical units are activated (e.g., the phonology of "own" and not its meaning is activated when shown the word "shown"). However, again this point should not influence the interpretation of the orthographic and the phonological effect in our Chinese picture-word naming experiments. In all of the related distractor conditions in our experiments, only the formal properties of the phonetic radicals differed systematically and the meaning of the phonetic radicals were all unrelated to the target. Therefore, we propose that our results do not speak only to the mechanisms of picture-word naming in Mandarin, but to this process more generally.

Our findings that both pure phonological distractors and pure orthographic distractors produce robust facilitation have important theoretical implications. We mentioned in the Introduction that it is a commonly held notion that the phonological facilitation effect in the picture-word interference paradigm is an output effect, at the level of retrieval of the target's phonological nodes. This assumption has led researchers to make inferences about the phonological encoding stage of production by manipulating phonological relatedness in this experimental paradigm. Our results, together with Lupker's (1982) study, suggest that this classical assumption of the phonological effect may be inaccurate, or at least must be considered with extreme caution. Because previous studies have used words that are both phonologically and orthographically related to the target, the facilitation effects described in the literature are most likely a mixture of effects occurring at multiple stages, including the lexical selection stage and the phonological output stage. Theoretical arguments that were based on conventional assumptions about the phonological facilitation effect need to be reevaluated (e.g., Costa \& Caramazza, 2002; Starreveld \& La Heij, 1995). It is important to keep in mind that without teasing apart orthographic and phonological relatedness, any facilitation effect observed is a mixture of effects from different sources and at different stages of processing. With this new understanding it will be possible to use the picture-word naming task to systematically investigate the interaction between phonological and orthographic processes in word recognition and speech production. 


\section{APPENDIX A}

Table A.1. Stimuli used in Experiment 1

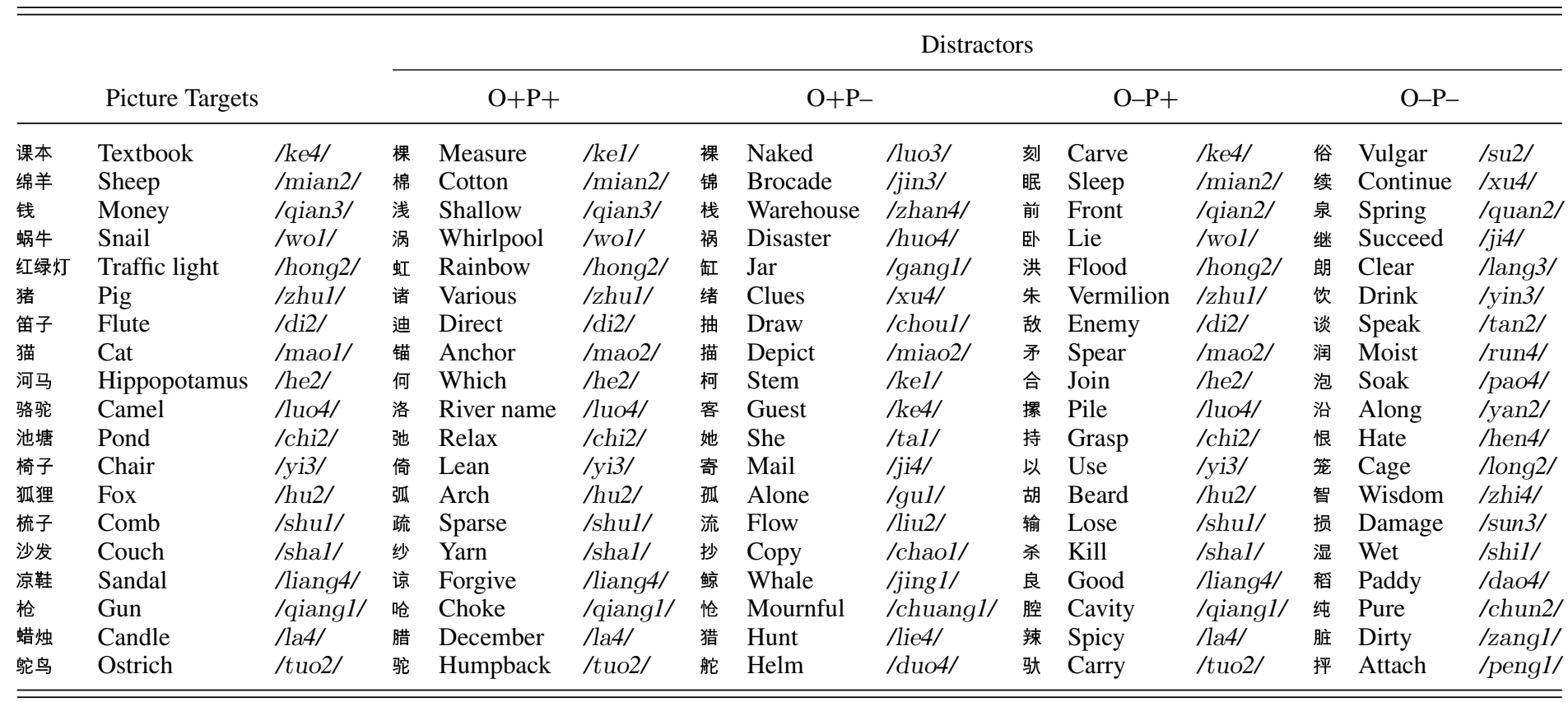

Note: $\mathrm{O}+\mathrm{P}+$, a word that was both orthographically and phonologically related to the picture name; $\mathrm{O}-\mathrm{P}+$, a word that was phonologically related but orthographically dissimilar to the picture name; $\mathrm{O}+\mathrm{P}-$, a word that was orthographically related but phonologically dissimilar to the picture name; and $\mathrm{O}-\mathrm{P}-$, a word that was neither orthographically or phonologically related to the picture name. 
Table A.2. Stimuli used in Experiment 2

\begin{tabular}{|c|c|c|c|c|c|c|c|c|c|c|c|c|c|c|}
\hline & & & \multicolumn{12}{|c|}{ Distractors } \\
\hline \multicolumn{3}{|c|}{ Picture Targets } & \multicolumn{3}{|c|}{$\mathrm{O}+\mathrm{P}+$} & \multicolumn{3}{|c|}{$\mathrm{O}+\mathrm{P}-$} & \multicolumn{3}{|c|}{$\mathrm{O}-\mathrm{P}+$} & \multicolumn{3}{|c|}{$\mathrm{O}-\mathrm{P}-$} \\
\hline 篮子 & Basket & /lan2/ & 蓝 & Blue & /lan2/ & 监 & Threshold & /kan3/ & 岗 & Haze & /lan2/ & 贡 & Tribute & /gongl/ \\
\hline 玫瑰 & Rose & /mei2/ & 枚 & Piece & /mei2/ & 攻 & Attack & /gongl/ & 煤 & Coal & /mei2/ & 驱 & Drive & /qull \\
\hline 课本 & Textbook & /ke4/ & 稞 & Grain & /ke4/ & 踝 & Ankle & /huai2/ & 磕 & Kneel & /ke4/ & 逻 & Patrol & /luo2/ \\
\hline 骆驼 & Camel & /luo4/ & 络 & Twine & /luo4/ & 骼 & Bone & /ge2/ & 螺 & Oyster & /luo4/ & 覆 & Cover & /fu4/ \\
\hline 狗 & Dog & /gou3/ & 枸 & Berryseed & /gou3/ & 拘 & Arrest & /jul/ & 垢 & Dirt & /gou3/ & 枕 & Pillow & /zhen3/ \\
\hline 蜗牛 & Snail & /wol/ & 窝 & Nest & /wol/ & 锅 & Pot & /guol/ & 沃 & Fertile & /woll & 浑 & Muddy & /hun2/ \\
\hline 烟灰缶 & Ashtray & /yanl/ & 胭 & Blush & /yanl/ & 恩 & Favor & /enl/ & 淹 & Drown & /yanl/ & 偿 & Compensate & /chang2/ \\
\hline 猪 & Pig & Izhul/ & 著 & Compose & /zhul/ & 堵 & Block & /du3/ & 祝 & Bless & /zhul/ & 银 & Silver & /yin2/ \\
\hline 松鼠 & Squirrel & /songl/ & 讼 & Sue & /songl/ & 蚣 & & /gongl/ & 宋 & & /songl/ & 神 & God & /shen2/ \\
\hline 河马 & Hippopotmus & /he2/ & 呵 & Breath & /he2/ & 阿 & & /al/ & 喝 & Drink & /he2/ & 粗 & Thick & /cul/ \\
\hline 池塘 & Pond & /chi2/ & 驰 & Gallop & /chi2/ & 他 & $\mathrm{He}$ & /tall & 迟 & Late & /chi2/ & 烤 & Roast & /kao3/ \\
\hline 桶 & Barrel & /tong3/ & 捅 & Poke & /tong3/ & 涌 & Gush & /yong3/ & 统 & Gather & /tong3/ & 绊 & Stumble & /ban4/ \\
\hline 沙发 & Couch & /shal/ & 砂 & Sand & /shal/ & 吵 & Noise & /chao3/ & 鞄 & Evil & /shal/ & 肠 & Intestines & /chang2/ \\
\hline 凉鞋 & Sandal & /liang2/ & 晾 & Expose & /liang2/ & 掠 & Plunder & /lue4/ & 亮 & Bright & /liang2/ & 滴 & Drop & /dill \\
\hline 蝎子 & Scorpion & /xiel/ & 歇 & Rest & /xiel/ & 渴 & Thirsty & /ke3/ & 些 & Some & /xiel/ & 妹 & Sister & /mei4/ \\
\hline 鹅 & Goose & /e2/ & 娥 & Lady & /e2/ & 哦 & & /wol/ & 额 & Forehead & /e2/ & 慷 & Generous & /kangl/ \\
\hline 桃子 & Peach & /tao2/ & 逃 & Flee & /tao2/ & 姚 & & /уао2/ & 套 & Cover & /tao2/ & 纠 & Entangle & /jiul/ \\
\hline 枪 & Gun & /qiangl/ & 跑 & Stagger & /qiang4/ & 创 & Invent & /chuang4/ & 镈 & Clang & /qiangl/ & 泳 & Swim & /yong3/ \\
\hline 啤酒 & Beer & /pi2/ & 脾 & Spleen & /pi2/ & 碑 & Tombstone & /beil/ & 皮 & Skin & /pi2/ & 辉 & Shine & /huil/ \\
\hline
\end{tabular}

Note: $\mathrm{O}+\mathrm{P}+$, a word that was both orthographically and phonologically related to the picture name; $\mathrm{O}-\mathrm{P}+$, a word that was phonologically related but orthographically dissimilar to the picture name; $\mathrm{O}+\mathrm{P}-$, a word that was orthographically related but phonologically dissimilar to the picture name; and $\mathrm{O}-\mathrm{P}-$, a word that was neither orthographically or phonologically related to the picture name. 


\section{ACKNOWLEDGMENTS}

The research reported here was supported by PCSIRT Grant IRT0710 and NSFC Grant 30700224 (to Y.B.) and NIH Grant DC04542 (to A.C.). The results were presented at the 18th Annual CUNY Sentence Processing Conference.

\section{NOTES}

1. In the examples given for the picture-word interference paradigm, underlining and capitalization will be used for distractors, and quotation marks will be used for picture target names.

2. Although in this paper we focus on the confounding between orthographic and phonological relatedness in visually presented distractors, analogous problems exist in the auditory version of the paradigm (see relevant discussions on the difference between the visual and auditory version of picture-word interference in Damian \& Martin, 1999; Starreveld, 2000). When the distractor is presented auditorily, the confounding of the orthographic relatedness may play a less critical role than it does in the visual version, because the activation of the orthographic properties is much less significant (but see Seidenberg \& Tanenhaus, 1979). However, during the auditory perception process of the phonological distractor (e.g., /kæp/), the lexical nodes of all similar words (cap, captain, capital, cat, cab) are activated (e.g., Marslen-Wilson, 1987, 1990). The target words are usually also in this cohort. Therefore, it is not clear whether the facilitation by such phonological distractors is due to the activation of the target lexical node, the activation of the target phonological segments, or both.

3. The numbers in the phonetic transcripts represent the tones of the syllables. There are four tones in Mandarin Chinese: 1 represents the flat tone, 2 the rising tone, 3 the falling then rising tone, and 4 the falling tone; 0 indicates an unstressed syllable with a neutral tone.

\section{REFERENCES}

Bi, Y., Han, Z., Weekes, B. S., \& Shu, H. (2007). The interaction between the semantic and the nonsemantic routes of reading: Evidence from Chinese. Neuropsychologia, 45, 2660-2673.

Bock, K., \& Levelt, W. J. M. (1994). Language production: Grammatical encoding. In M. Gernsbacher (Ed.), Handbook of psycholinguistics. New York: Academic Press.

Bub, D., Cancelliere, A., \& Kertesz, A. (1985). Whole-word and analytic translation of spelling-tosound in a non-semantic reader. In K. E. Patterson, J. C. Marshall, \& M. Coltheart (Eds.), Surface dyslexia. London: Erlbaum.

Caramazza, A. (1997). How many levels of processing are there in lexical access? Cognitive Neuropsychology, 14, 177-208.

Caramazza, A., Costa, A., Miozzo, M., \& Bi, Y. (2001). The specific-word frequency effect: Implications for the representation of homophones. Journal of Experimental Psychology: Learning, Memory, and Cognition, 27, 1430-1450.

Caramazza, A., \& Miozzo, M. (1997). The relation between syntactic and phonological knowledge in lexical access: Evidence from the "tip-of-the-tongue" phenomenon. Cognition, 64, 309-343.

Chen, H.-C., Cheung, S. L., \& Flores d'Arcais, G. B. (1995). Orthographic and phonological activation in recognizing Chinese characters. Psychological Research, 58, 144-153.

Cheng, C. M., \& Shih, S. I. (1998). The nature of lexical access in Chinese: Evidence from experiments on visual and phonological priming in lexical judgement. In I. M. Liu, H. C. Chen, \& M.-J. Chen (Eds.), Cognitive aspects of the Chinese language (Vol. 1, pp. 1-14). Hong Kong: Asian Research Service. 
Bi et al.: Picture-word interference

Coltheart, M. (1978). Lexical access in simple reading tasks. In G. Underwood (Ed.), Strategies of information processing. London: Academic Press.

Coltheart, M., Rastle, K., Perry, C., Langdon, R., \& Ziegler, J. (2001). DRC: A dual route cascaded model of visual word recognition and reading aloud. Psychological Review, 108, 204-256.

Costa, A., \& Caramazza, A. (2002). The production of noun phrases in English and Spanish: Implications for the scope of phonological encoding in speech production. Journal of Memory and Language, 46, 178-198

Costa, A., Mahon, B., Savova, V., \& Caramazza, A. (2003). Level of categorization effect: A novel effect in the picture-word interference paradigm. Language and Cognitive Processes, 18, 205-233.

Damian, M. F., \& Martin, R. C. (1999). Semantic and phonological codes interact in single word production. Journal of Experimental Psychology: Learning, Memory, and Cognition, 25, 345361.

DeFrancis, J. (1989). Visible speech: The diverse oneness of writing systems. Honolulu: University of Hawaii Press.

Dell, G. S. (1986). A spreading activation theory of retrieval in sentence production. Psychological Review, 93, 283-321.

Feng, G., Miller, K., Shu, H., \& Zhang, H. (2001). Rowed to recovery: The use of phonological and orthographic information in reading Chinese and English. Journal of Experimental Psychology: Learning, Memory, and Cognition, 27, 1079-1100.

Finkbeiner, M., \& Caramazza, A. (2006). Now you see it, now you don't: On turning semantic interference into facilitation in a Stroop-like task. Cortex, 42, 790-796.

Forster, K. I. (1976). Accessing the mental lexicon. In R. J. Wales \& E. W. Walker (Eds.), New approaches to language mechanisms (pp. 257-287). Amsterdam: North-Holland.

Forster, K. I., \& Forster, J. C. (2003). DMDX: A Windows display program with millisecond accuracy. Behavior Research Methods, Instruments, and Computers, 35, 116-124.

Garrett, M. (1980). Levels of processing in sentence production. In Language production: Vol. 1. Speech and talk. New York: Academic Press.

Glaser, W. R., \& Dungelhoff, F. J. (1984). The time course of picture-word interference. Journal of Experimental Psychology: Human Perception and Performance, 10, 640-654.

Glaser, W. R., \& Glaser, M. O. (1989). Context effects on Stroop-like word and picture processing. Journal of Experimental Psychology: General, 118, 13-42.

Harley, T. A. (1999). Will one stage and no feedback suffice in lexicalization? Behavioral and Brain Sciences, 22, 45 .

Hillis, A. E., \& Caramazza, A. (1995). Converging evidence for trhe interation of semantic and sublexical phonological information in accessing lexical prepresentations for spoken output. Cognitive Neuropsychology, 12, 187-227.

Hue, C.-W. (1992). Recognition processes in character naming. In H.-C. Chen \& O. J. L. Tzeng (Eds.), Language processing in Chinese (pp. 93-107). Amsterdam: North-Holland.

Institute of Language Teaching and Research. (1986). Xiandai Hanyu Pinlv Cidian (Modern Chinese frequency dictionary). Beijing: Beijing Language Institute Press.

Janssen, N., Schirm, W., Mahon, B. Z., \& Caramazza, A. (2008). The semantic interference effect in the picture-word interference paradigm: Evidence for the response selection hypothesis. Journal of Experimental Psychology: Learning, Memory, and Cognition, 34, 249256.

Law, S. P., \& Wong, R. (2005). A model-driven treatment of a Cantonese-speaking dyslexic patient with impairment to the semantic and nonsemantic pathways. Cognitive Neuropsychology, 22, 95-110.

Lee, C. Y., Tsai, J. L., Kuo, W. J., Yeh, T. C., Wu, Y. T., Ho, L. T., et al. (2004). Neuronal correlates of consistency and frequency effects on Chinese character naming: An event-related fMRI study. NeuroImage, 23, 1235-1245.

Lee, C. Y., Tsai, J. L., Su, S. C., Tzeng, O., \& Hung, D. (2005). Consistency, regularity and frequency effects in naming Chinese characters. Language and Linguistics, 6, 175-197.

Levelt, W. J. M. (1989). Speaking: From intention to articulation. Cambridge, MA: MIT Press.

Levelt, W. J. M., Roelofs, A., \& Meyer, A. S. (1999). A theory of lexical access in speech production. Behavioral and Brain Sciences, 22, 1-75.

Li, D. (1993). A study of Chinese characters. Beijing: Peking University Press. 
Bi et al.: Picture-word interference

Li, G. Y., \& Liu, R. S. (1988). Hanzi Xinxi Zidian (Chinese character information dictionary). Beijing: Science Press.

Lukatela, G., \& Turvey, M. T. (1994a). Visual lexical access is initially phonological: I. Evidence from associative priming by words, homophones, and pseudohomophones. Journal of Experimental Psychology: General, 123, 107-128.

Lukatela, G., \& Turvey, M. T. (1994b). Visual lexical access is initially phonological: I. Evidence from phonological priming by homophones and pseudohomophones. Journal of Experimental Psychology: General, 123, 331-353.

Lupker, S. J. (1982). The role of phonetic and orthographic similarity in picture-word interference. Canadian Journal of Psychology, 36, 349-367.

Mahon, B. Z., Costa, A., Peterson, R., Vargas, K., \& Caramazza, A. (2007). Lexical selection is not by competition: A reinterpretation of semantic interference and facilitation effects in the picture-word interference paradigm. Journal of Experimental Psychology: Learning, Memory, and Cognition, 33, 503-535.

Marslen-Wilson, W. D. (1987). Functional parallellism in spoken word recognition. Cognition, 25, 71-102.

Marslen-Wilson, W. D. (1990). Activation, competition, and frequency in lexical access. In G. T. M. Altmann (Ed.), Cognitive models of speech processing: psycholinguistic and computational perspectives. Cambridge, MA: MIT Press.

Massaro, D. W., \& Cohen, M. M. (1991). Integration versus interactive activation: The joint influence of stimulus and context in perception. Cognitive Psychology, 23, 558-614.

McClelland, J. L., \& Rumelhart, D. E. (1981). An interactive activation model of context effects in letter perception: Part 1. An account of basic findings. Psychological Review, 88, 375407.

Meyer, A. S., \& Schriefers, H. (1991). Phonological facilitation in picture-word interference experiments: Effects of stimulus onset asynchrony and types of interfering stimuli. Journal of Experimental Psychology: Learning, Memory, and Cognition, 17, 1146-1160.

Miozzo, M., \& Caramazza, A. (2003). When more is less: A counterintuitive effect of distractor frequency in the picture-word interference paradigm. Journal of Experimental Psychology: General, 132, 228-252.

Morton, J. (1969). Interaction of information in word recognition. Psychological Review, 76, 165-178.

Peng, D., Yang, H., \& Chen, Y. (1994). Consistency and phonetic independency effects in naming task of Chinese phonograms. In Q. C. Jing, H. C. Zhang, \& D. L. Peng (Eds.), Information processing of Chinese language. Beijing: Beijing Normal University Publishing.

Perfetti, C. A., \& Tan, L. H. (1998). The time course of graphic, phonological, and semantic activation in Chinese character identification. Journal of Experimental Psychology: Learning, Memory, and Cognition, 24, 101-118.

Perfetti, C. A., \& Zhang, S. (1995). Very early phonological activation in Chinese reading. Journal of Experimental Psychology: Learning, Memory, and Cognition, 21, 24-33.

Posnansky, C. J., \& Rayner, K. (1978). Visual vs. phonemic contributions to the importance of the initial letter in word identification. Bulletin of the Psychonomic Society, 11, 188-190.

Rapp, B., \& Goldrick, M. (2000). Discreteness and interactivity in spoken word production. Psychological Review, 107, 460-499.

Roelofs, A. (1992). A spreading-activation theory of lemma retrieval in speaking. Cognition, 42, 107-142.

Roelofs, A. (1997). The WEAVER model of word-form encoding in speech production. Cognition, 64, 249-284.

Roelofs, A., Meyer, A. S., \& Levelt, W. J. M. (1996). Interaction between semantic and orthographic factors in conceptually driven naming: Comment on Starreveld and La Heij (1995). Journal of Experimental Psychology: Learning, Memory, and Cognition, 22, 246-251.

Schriefers, H., Meyer, A. S., \& Levelt, J. M. (1990). Exploring the time course of lexical access in language production: Picture-word interference studies. Journal of Memory and Language, $29,86-102$.

Seidenberg, M. S. (1985). The time course of phonological code activation in two writing systems. Cognition, 19, 1-30.

Seidenberg, M. S., \& Tanenhaus, M. K. (1979). Orthographic effects on rhyme monitoring. Journal of Experimental Psychology: Human Learning and Memory, 5, 546-554. 
Bi et al.: Picture-word interference

Shen, D., \& Forster, K. I. (1999). Masked phonological priming in reading Chinese words depends on the task. Language and Cognitive Processes, 14, 429-459.

Shu, H., \& Zhang, H. (1987). The phonological processing of Chinese characters in skilled readers. Acta Psychologia Sinica, 3, 297-304.

Snodgrass, J. G., \& Vanderwart, M. (1980). A standardized set of 260 pictures: Norms for name agreement, image agreement, familiarity, and visual complexity. Journal of Experimental Psychology: Human Learning and Memory, 6, 174-215.

Starreveld, P. A. (2000). On the interpretation of onsets of auditory context effects in word production. Journal of Memory and Language, 42, 497-525.

Starreveld, P. A., \& La Heij, W. (1995). Semantic interference, orthographic facilitation and their interaction in naming tasks. Journal of Experimental Psychology: Learning, Memory, and Cognition, 21, 686-698.

Starreveld, P. A., \& La Heij, W. (1996). The locus of orthographic-phonological facilitation: Reply to Roelofs, Meyer, and Levelt (1996). Journal of Experimental Psychology: Learning, Memory, and Cognition, 22, 252-255.

Stroop, J. R. (1935). Studies of interference in serial verbal reactions. Journal of Experimental Psychology, 18, 643-662.

Tan, L. H., Hoosain, R., \& Peng, D.-L. (1995). Role of early presemantic phonological code in Chinese character identification. Journal of Experimental Psychology: Learning, Memory, and Cognition, 21, 43-54.

Wang, W. S.-Y. (1973). The Chinese language. Scientific American, 228, 50-60.

Weekes, B. S., \& Chen, H. (1999). Surface dyslexia in Chinese. Neurocase, 5, 101-112.

Weekes, B. S., Davies, R. A., \& Chen, M.-J.,(2002). Picture-word interference effects on naming in Chinese. In H. S. R. Kao, C. K. Leong, \& D.-G. Gao (Eds.), Cognitive neuroscience studies of the Chinese language (pp. 101-127). Hong Kong: Hong Kong University Press.

Wong, K. F. E., \& Chen, H.-C. (1999). Orthographic and phonological processing in reading Chinese text: Evidence from eye fixations. Language and Cognitive Processes, 14, 461-480.

Yin, B., \& Rohsenow, J. S. (1994). Modern Chinese characters. Beijing: Sinolingua.

Yin, W., \& Butterworth, B. (1992). Deep and surface dyslexia in Chinese. In H. C. Chen \& O. J. L. Tzeng (Eds.), Language processing in Chinese (pp. 349-366). Amsterdam: North-Holland.

Zhou, X., \& Marslen-Wilson, W. (1999a). Phonology, orthography, and semantic activation in reading Chinese. Journal of Memory and Language, 41, 579-606.

Zhou, X., \& Marslen-Wilson, W. (1999b). Sublexical processing in reading Chinese. In J. Wang, A. Inhoff, \& H.-C. Chen (Eds.), Reading Chinese script: A cognitive analysis (pp. 37-63). Hillsdale, NJ: Erlbaum.

Zhou, X., Marslen-Wilson, W., Taft, M., \& Shu, H. (1999). Morphology, orthography, and phonology in reading Chinese compound words. Language and Cognitive Processes, 14, 525-565.

Zhou, X., Shu, H., Bi, Y., \& Shi, D. (1999). Is there phonologically mediated access to lexical semantics in reading Chinese? In J. Wang, A. Inhoff, \& H.-C. Chen (Eds.), Reading Chinese script: A cognitive analysis (pp. 135-171). Hillsdale, NJ: Erlbaum.

Zhou, X., Zhuang, J., Wu, J., \& Yang, D. (2003). Phonological, orthographic and semantic activation in the speech production of Chinese. Acta Psychologica Sinica, 6, 712-718.

Zhu, X. (1988). Analysis of cueing function of phonetic components in modern Chinese. In X. Yuan (Ed.), Proceedings of the Symposium on the Chinese Language and Characters (pp. 85-99). Beijing: Guang Ming Daily Press. 